\title{
A nested case-control study of adjuvant hormonal therapy persistence and compliance, and early breast cancer recurrence in women with stage I-III breast
} cancer

\author{
T I Barron ${ }^{*}, 1$, C Cahir ${ }^{1}$, L Sharp ${ }^{2}$ and K Bennett ${ }^{1}$ \\ ${ }^{1}$ Department of Pharmacology and Therapeutics, Trinity College, University of Dublin, Dublin, Ireland and ${ }^{2}$ National Cancer \\ Registry Ireland, Cork, Ireland
}

Background: Non-persistence and non-compliance are common in women prescribed hormonal therapy for breast cancer, but little is known about their influence on recurrence.

Methods: A nested case-control study of associations between hormonal therapy non-persistence and non-compliance and the risk of early recurrence in women with stage I-III breast cancer was undertaken. Cases, defined as women with a breast cancer recurrence within 4 years of hormonal therapy initiation, were matched to controls (1:5) by tumour stage and age. Conditional logistic regression was used to examine associations between early recurrence and hormonal therapy non-persistence and noncompliance.

Results: Ninety-four women with breast cancer recurrence were matched to 458 controls. Women who were non-persistent ( $\geqslant 180$ days without hormonal therapy) had a significantly increased adjusted recurrence odds ratio (OR) of 2.88 (95\%Cl 1.11, 7.46$)$ compared with persistent women. There was no significant association between low compliance $(\mathrm{OR} 1.30 ; 95 \% \mathrm{Cl} 0.74,2.30)$ and breast cancer recurrence.

Conclusion: Hormonal therapy non-persistence is associated with a significantly higher risk of early recurrence in women with stage I-III oestrogen receptor (ER)-positive breast cancer. This finding is consistent with results from randomized studies of hormonal therapy treatment duration and suggests that interventions to target modifiable risk factors for non-persistence are required.

\begin{abstract}
Adjuvant hormonal therapy reduces the annual breast cancer recurrence rate for women with oestrogen receptor (ER)-positive early breast cancer by up to $50 \%$, with at least 5 , and up to 10 , years of treatment required to achieve the optimal benefit (EBCTG, 2005; Davies et al, 2013). Despite the efficacy of hormonal therapy, as many as one in seven women prescribed adjuvant treatment will have a breast cancer recurrence within 5 years of treatment
\end{abstract}

initiation (EBCTG, 2005), with evidence suggesting a peak in recurrences occurring at 2-3 years post diagnosis (Saphner et al, 1996; Debled et al, 2007; Kennecke et al, 2008; Mansell et al, 2009). Various tumour-related factors-including large size, positive lymph node status and high grade-have been identified as predictors of early breast cancer recurrence (Saphner et al, 1996; Debled et al, 2007; Kennecke et al, 2008; Mansell et al, 2009).

\section{*Correspondence: Dr TI Barron; Email: barront@tcd.ie}

Received 11 April 2013; revised 31 July 2013; accepted 9 August 2013; published online 3 September 2013 
Early treatment discontinuation (non-persistence) and sub-optimal treatment execution (non-compliance) are both common in women prescribed hormonal therapies for breast cancer.(Partridge et al, 2003; Barron et al, 2007) Many women cite treatment side effects as the primary reason for not taking their hormonal therapy as prescribed (Grunfeld et al, 2005; Henry et al, 2012). Studies indicate that up to $30 \%$ of women will discontinue hormonal treatments within 3-5 years of initiation (Barron et al, 2007; Owusu et al, 2008), and that as many as $20 \%$ of women regularly omit at least one in five of their prescribed doses while on treatment (Partridge et al, 2003). A small number of studies have suggested that reduced hormonal therapy exposure, due to either non-persistence or non-compliance, is associated with an increased risk of mortality (McCowan et al, 2008; Dezentjé et al, 2010; Hershman et al, 2011; Weaver et al, 2012; Makubate et al, 2013). However, little is known about the influence of non-persistence and non-compliance on the risk of early breast cancer recurrence (Makubate et al, 2013).

The aim of this study was to examine associations between hormonal therapy non-persistence and non-compliance and the risk of early recurrence in women with ER-positive breast cancer, in analyses adjusted for other predictors of recurrence.

\section{SUBJECTS AND METHODS}

Setting and data sources. The study was conducted using patient records from the National Cancer Registry Ireland (NCRI), which are linked to prescription dispensing data from Ireland's Primary care reimbursement services (PCRS) pharmacy claims database. Patient records from the PCRS and NCRI databases were linked using probabilistic matching (AutoMatch, Matchware Technologies, Inc., Silver Spring, MD, USA). NCRI records detailed information on all incident cancers diagnosed in the population usually resident in Ireland. Information on patient characteristics, tumour details, treatment received and death is collected by trained hospital-based tumour registration officers (TRO) from multiple sources including pathology and radiology reports, medical records and death certificates. The accuracy and completeness of NCRI data has been evaluated and described (NCRI, 2012). The PCRS pharmacy claims database is an administrative database of electronic claims from pharmacies for financial reimbursement of dispensed medications. The PCRS is responsible for reimbursement of claims made under the General Medical Services (GMS) community drug scheme, which provides universal healthcare to approximately one-third (1.4 million) of the Irish population. Eligibility for the GMS scheme is through means test and age $(\geqslant 70$ years). The GMS population is therefore older and more socioeconomically deprived than the full Irish population. The PCRS pharmacy claims database records details of all prescription drugs dispensed to patients with eligibility for the scheme. Drugs are coded according to WHO-ATC classifications (WHO, 2010). The use for research of anonymised data held by the NCRI is covered by the Health (Provision of Information) Act 1997.

Study design. A case-control study design, nested within a cohort was used. Women between the ages of 40 and 80 years were eligible for inclusion in the study cohort if they had a diagnosis of stage I-III, ER-positive breast cancer (ICD-10 C50) (Greene et al, 2002), between 1 January 2002 and 31 December 2006; had continuous GMS eligibility from at least 1 year prior to diagnosis; had received tumour-directed surgery within 1 year of breast cancer diagnosis (lumpectomy or mastectomy; Appendix 1); and had filled at least one prescription for hormonal therapy within 1 year of breast cancer diagnosis and at least 90 days prior to the end of follow-up. Women were excluded if they had a prior invasive cancer other than non-melanoma skin cancer. Patients were followed up until breast cancer recurrence, death from any cause, 31 December 2007 or 4 years from hormonal therapy initiation, whichever occurs first.

Covariate definitions. NCRI data was used to classify women by tumour stage (I, IIa, IIb, IIIa and IIIb-c) (Greene et al, 2002); grade (low, intermediate, high and unspecified); ER, PR, HER-2 status (positive, negative and unspecified; Appendix-1); the receipt of radiation therapy in the year post diagnosis (yes, no); and the receipt of chemotherapy prior to hormonal therapy initiation (yes, no). Information on age at diagnosis (years), smoking status (non-smoker, past, current and unspecified) and socioeconomic status was also available. Socioeconomic status was defined according to census-based National Deprivation Index for the area of residence at diagnosis (5-point scale; 1 least deprived, 5 most deprived) (Kelly and Teljeur, 2007). Prescription refill data was used to identify other, potentially confounding, medication use in the year prior to breast cancer diagnosis (exposed, unexposed; Appendix-1): statins (lipophilic, hydrophilic) and aspirin. The number of medication classes (WHO-ATC level 5) dispensed in the year prior to breast cancer diagnosis was used as a measure of comorbidity (Schneeweiss et al, 2001).

Case-control selection. Cases were defined as women with a local or distant breast cancer recurrence within 4 years of hormonal therapy initiation. The date and site of breast cancer recurrence was identified by TROs from two sources; first, from pathology reports of biopsied breast tumour metastases automatically reported by pathology laboratories to the NCRI, and second, from clinical notes and radiology reports. Controls were matched to cases in a ratio of $5: 1$ by tumour stage and age (5-year calliper) using incidence density sampling without replacement (Robins et al, 1986; Bergstralh and Kosanke, 1995). Controls had to be alive and without recurrence at time of a case's recurrence. The date of recurrence for a case was assigned as the index date for each matched control.

Hormonal therapy medication taking behaviours. All prescriptions for selective oestrogen receptor modulators (SERMs; tamoxifen and toremifene) and aromatase inhibitors (AIs; anastrozole, letrozole and exemestane) dispensed to women from the time of breast cancer diagnosis to the end of follow-up were identified from the PCRS database (Appendix 1). The date of dispensing, type of hormonal therapy and number of days' supply on each prescription were abstracted. Using this data a longitudinal daily history of hormonal therapy availability was assembled for each woman by assigning the days' supply from each prescription to sequential days from the date of dispensing (Peterson et al, 2007). In cases where women switched hormonal therapies these were evaluated as a single contiguous treatment episode. These longitudinal daily histories of hormonal therapy availability were used to calculate three measures of medication-taking behaviour: (i) persistence: the last day of hormonal therapy availability prior to the case/control index date was identified, and the cumulative number of consecutive non-persistent days from this date to the index date was used to classify women as persistent $(<180$ day gap) or non-persistent ( $>180$ day gap); (ii) compliance: the proportion of days covered up to the first of either the case/control index date or the date of non-persistence was identified for each patient (Benner et al, 2002; Barron et al, 2010); (iii) a second measure of compliance was also calculated; for clarity this is referred to as cumulative exposure: the total quantity of adjuvant hormonal therapy taken by a woman is determined by both the duration of treatment (persistence) and the quality of treatment execution during this time (compliance); to reflect this, the cumulative hormonal therapy exposure was defined as the proportion of days covered up to the case/control index date (i.e. including time after non-persistence in women who had 
discontinued treatment). Compliance and cumulative exposure were stratified by tertiles for analyses.

Statistical analysis. The frequency and proportion of cases and controls were tabulated by clinical and sociodemographic covariates and by hormonal therapy persistence, compliance and cumulative exposure categories. Means and percentages for controls were weighted by the inverse number of controls matched to each case. Standardized differences $(d)$ were used to assess balance in measured characteristics between matched cases and controls (Austin, 2008). Univariate and multivariate conditional logistic regression was used to estimate odds ratios (OR) with $95 \%$ confidence intervals (CI) for associations between breast cancer recurrence in the 4 years after hormonal therapy treatment initiation and hormonal therapy (i) persistence, (ii) compliance and (iii) cumulative exposure (Rothman et al, 2008). These ORs have a rate ratio interpretation, as controls were matched on person time at risk (Pearce, 1993). Covariates were included in multivariate models based on prior knowledge of clinical predictors of early breast cancer recurrence (tumour grade, PR, HER-2, chemotherapy, comorbidity score) (Saphner et al, 1996; Debled et al, 2007; Kennecke et al, 2008; Mansell et al, 2009), demographic predictors of breast cancer outcomes (smoking status, socioeconomic status) (Bradley et al, 2002; Braithwaite et al, 2012) and drug exposures previously associated with breast cancer outcomes (statins, aspirin) (Holmes et al, 2010; Ahern et al, 2011). To avoid over fitting, backwards stepwise elimination of covariates with a threshold $\alpha$-level of $>0.2$ was used to select the final multivariate model (Maldonado and Greenland, 1993). All analyses were performed with SAS, version 9.2 (SAS Institute Inc, Cary, NC, USA). Results were considered statistically significant at a two-sided $\alpha$-level of 0.05 .

Sensitivity analyses. Probabilistic sensitivity analyses were undertaken to estimate the potential impact of misclassification of breast cancer recurrence on the primary analysis using the SAS macro SENSMAC available at https:/sites.google.com/site/biasanalysis/ sensmac (Lash and Fink, 2003; Fox et al, 2005; Lash et al, 2009). The parameters for these sensitivity analyses were specified based on (i) estimates from validation studies in external populations using similar methods for ascertainment of recurrence, (ii) knowledge of recurrence assessment practices by NCRI tumour registration officers and (iii) numerical constraints of the data (Jurek et al, 2009). The identification of breast cancer recurrence by medical record abstraction has been shown to have high specificity
(96\%) but imperfect sensitivity (90\%) (Lash et al, 2007; Thwin et al, 2007; Bosco et al, 2009). Using these values to guide parameter estimates it was assumed that recurrence assessment by NCRI TROs would have a lower sensitivity but similar specificity. The influence of non-differential misclassification of recurrence was then evaluated (5000 simulations) with sensitivity and specificity drawn from the same trapezoidal distributions. The possible range for these distributions could not be evaluated from prior data and they were conservatively set with a wide dispersion at $0.70-0.90$ for sensitivity (mode $0.75-0.85$ ) and $0.94-1.00$ for specificity (mode 0.96-0.98). In differential analyses it was assumed a higher sensitivity and specificity would be achieved for women with higher compliance/persistence. A correlation of 0.8 was specified for the similarity between sensitivity and specificity. Finally, the distributions of sensitivity and specificity were adjusted upwards so that no more than $10 \%$ of simulations produced impossible corrected data (i.e. negative counts). The final parameters used are presented in Table 3. In addition to these probabilistic sensitivity analyses, analyses were also repeated including patients of any age.

\section{RESULTS}

A flow chart outlining the cohort selection is presented in Figure 1. The characteristics of women included in the cohort $(n=1376)$ are presented in Table 1. The mean age of women at diagnosis was 65.0 years. Radiation and chemotherapy were received by $68.0 \%$ and $32.6 \%$ of women, respectively. Aromatase inhibitors were prescribed as first-line hormonal therapy to $50.2 \%$ of women. During follow-up, $44.3 \%$ of patients switched from a SERM to an AI and $8.7 \%$ switched from an AI to a SERM. In addition, $6.4 \%$ of women were non-persistent with treatment at the time of recurrence $(\geqslant 180$ day gap in treatment); the mean hormonal therapy compliance rate while persistent with treatment was $90.0 \%$ (s.d. =15.8\%); the mean cumulative exposure rate was $86.8 \%$ (s.d. $=20.8 \%)$. A total of 95 women had a breast cancer recurrence within 4 years of hormonal therapy initiation, translating into an overall recurrence rate of 25.6 per 1000 women-years. The most frequent recurrent metastatic site was bone $(48.4 \%)$, followed by liver (11.6\%), lung (8.4\%), brain (7.4\%) and local recurrence (7.4\%).

In the case-control analysis, 94 of the women with recurrence were successfully matched to 458 controls ( 89 cases had 5 controls each, 1 case had 4 controls, 2 cases had 3 controls, 1 case had 2

Women of any age with NCRI database record of invasive breast cancer, diagnosed 1 January 2002-

31 December 2006. Excluding women with prior invasive cancer, or breast cancer identified at death. $N=10558$

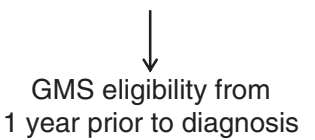

1 year prior to diagnosis

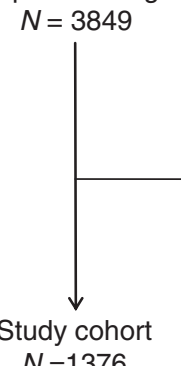

Exclude

Age $<40$ years $(N=425)$

Age $>80$ years $(N=635)$

Stage IV \& unspecified $(N=375)$

Estrogen receptor negative \& unspecified $(N=673)$

No surgery $(N=116)$

No hormonal therapy $(N=225)$

Recurrence within 90 days of hormonal therapy initiation $(N=24)$

$N=1376$

Figure 1. Flow chart showing study cohort inclusion and exclusion criteria. 
Table 1. Characteristics of full cohort, breast cancer recurrence cases and matched controls

\begin{tabular}{|c|c|c|c|}
\hline Characteristic & $\begin{array}{l}\text { Full cohort } \\
(n=1376)\end{array}$ & $\begin{array}{c}\text { Cases }^{a} \\
(n=94)\end{array}$ & $\begin{array}{l}\text { Controls }{ }^{a, b} \\
(n=458)\end{array}$ \\
\hline
\end{tabular}

Patient details

Age-mean (s.d.)

\begin{tabular}{|l|c|c|c|}
\hline Years & $65.0(10.2)$ & $64.3(10.0)$ & $64.3(10.1)$
\end{tabular}

Comorbidity-mean (s.d.)

\begin{tabular}{|l|c|c|c|}
\hline Drug classes & $8.4(6.3)$ & $9.0(7.1)$ & $8.1(6.1)^{\mathrm{c}}$ \\
\hline
\end{tabular}

\section{Smoking status (\%)}

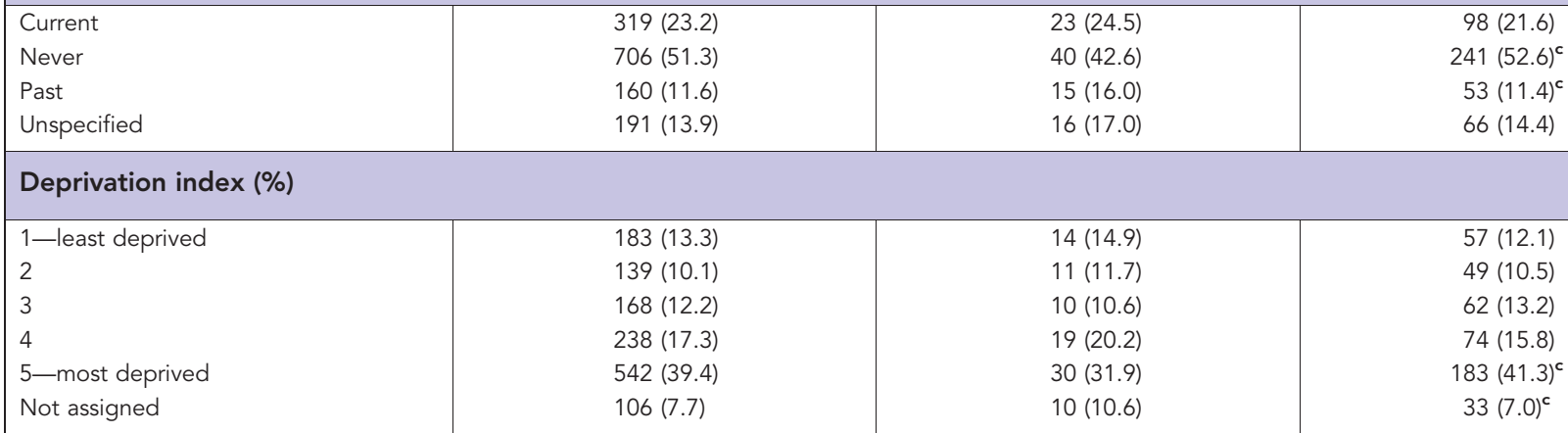

\section{Tumour details}

\section{Tumour stage $(\%)^{d}$}

\begin{tabular}{|c|c|c|c|}
\hline $\begin{array}{l}\text { I } \\
\text { Ila / IIb } \\
\text { IIla / IIIb-c }\end{array}$ & $\begin{array}{c}446(32.4) \\
447 / 316(32.5 / 23.0) \\
79 / 88(5.7 / 6.4)\end{array}$ & $\begin{array}{c}13(13.8) \\
28 / 29(29.8 / 30.9) \\
11 / 13(11.7 / 13.8)\end{array}$ & $\begin{array}{c}65(13.8) \\
140 / 145(29.8 / 30.9) \\
48 / 60(11.7 / 13.8)\end{array}$ \\
\hline \multicolumn{4}{|l|}{ Tumour grade (\%) } \\
\hline $\begin{array}{l}\text { Low } \\
\text { Intermediate } \\
\text { High } \\
\text { Unspecified }\end{array}$ & $\begin{array}{l}173(12.6) \\
743(54.0) \\
342(24.9) \\
118(8.6)\end{array}$ & $\begin{array}{c}6(6.4) \\
41(43.6) \\
38(40.4) \\
9(9.6)\end{array}$ & $\begin{array}{c}42(9.0) \\
246(53.2)^{c} \\
125(28.2)^{c} \\
45(9.6)\end{array}$ \\
\hline \multicolumn{4}{|l|}{ PR (\%) } \\
\hline $\begin{array}{l}\text { Negative } \\
\text { Positive } \\
\text { Unspecified }\end{array}$ & $\begin{array}{l}197(14.3) \\
919(66.8) \\
260(18.9)\end{array}$ & $\begin{array}{l}20(21.3) \\
54(57.4) \\
20(21.3)\end{array}$ & $\begin{array}{c}68(14.8) \\
300(65.6)^{c} \\
90(19.7)^{c}\end{array}$ \\
\hline \multicolumn{4}{|l|}{ HER-2 (\%) } \\
\hline $\begin{array}{l}\text { Negative } \\
\text { Positive } \\
\text { Unspecified }\end{array}$ & $\begin{array}{l}797(57.9) \\
128(9.3) \\
451(32.8)\end{array}$ & $\begin{array}{l}50(53.2) \\
11(11.7) \\
33(35.1)\end{array}$ & $\begin{array}{c}258(56.7) \\
43(9.1) \\
157(34.2)\end{array}$ \\
\hline \multicolumn{4}{|l|}{ Treatment details } \\
\hline $\begin{array}{l}\text { Chemotherapy (\%) } \\
\text { Radiation (\%) }\end{array}$ & $\begin{array}{l}449(32.6) \\
936(68.0)\end{array}$ & $\begin{array}{l}39(41.7) \\
60(63.8)\end{array}$ & $\begin{array}{l}187(41.5) \\
318(69.6)^{c}\end{array}$ \\
\hline \multicolumn{4}{|c|}{ First hormonal therapy (\%) } \\
\hline $\begin{array}{l}\text { Tamoxifen } \\
\text { Toremifene } \\
\text { Anastrozole } \\
\text { Letrozole } \\
\text { Exemestane }\end{array}$ & $\begin{array}{c}685(49.8) \\
0(0.0) \\
586(42.6) \\
99(7.2) \\
6(0.4)\end{array}$ & $\begin{array}{c}59(62.8) \\
0(0.0) \\
29(30.9) \\
6(6.4) \\
0(0.0)\end{array}$ & $\begin{aligned} 261 & (56.8) \\
0 & (0.0) \\
166 & (36.6) \\
28 & (6.0) \\
3 & (0.6)\end{aligned}$ \\
\hline \multicolumn{4}{|c|}{ Other drug exposures (\%) } \\
\hline $\begin{array}{l}\text { Aspirin } \\
\text { Statin hydrophilic } \\
\text { Statin lipophilic }\end{array}$ & $\begin{array}{c}357(25.9) \\
302(21.9) \\
36(2.6)\end{array}$ & $\begin{array}{c}23(24.5) \\
18(19.1) \\
1(1.1)\end{array}$ & $\begin{array}{r}117(25.7) \\
89(19.2) \\
17(3.6)^{c}\end{array}$ \\
\hline
\end{tabular}




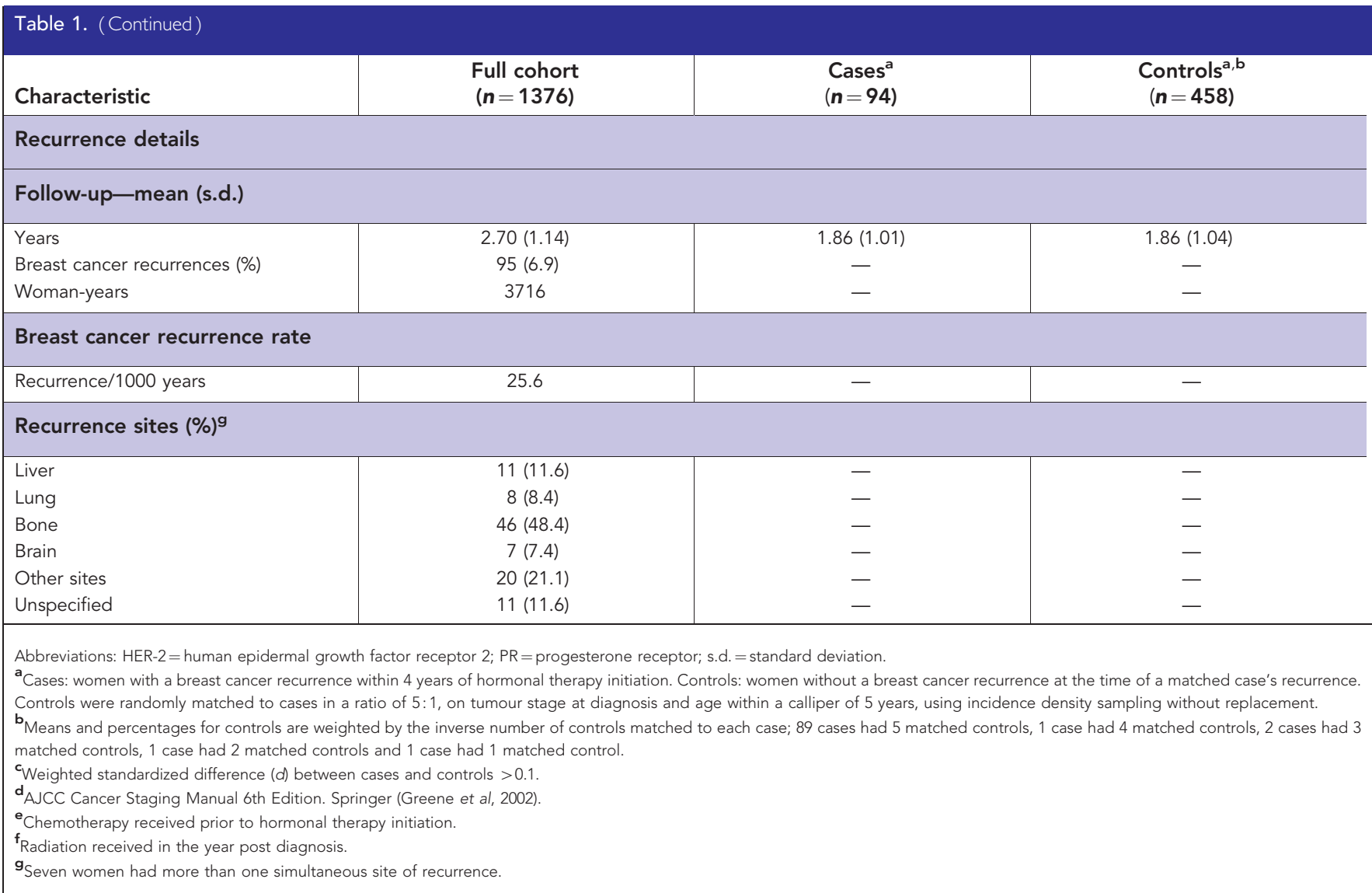

controls, 1 case had 1 control and 1 case had 0 controls). The characteristics of these cases and matched controls are presented in Table 1. Cases were more likely to have tumour characteristics previously associated with breast cancer recurrence such as higher grade or negative progesterone receptor status. In multivariate analyses of hormonal therapy compliance and persistence, adjusted for prognostic tumour and patient characteristics, breast cancer recurrence ORs were increased for women in the nonpersistent group and the lowest compliance tertile, although only associations with non-persistence reached formal statistical significance. Women who were non-persistent with treatment had a significantly increased adjusted recurrence OR of 2.88 (95\% CI 1.11, 7.46; 8 cases, 14 controls; Table 2) in comparison to women who persisted with treatment. Women in the lowest compliance tertile had a non-significant adjusted breast cancer recurrence OR of 1.30 (95\% CI 0.74, 2.30; 36 cases, 148 controls), in comparison to women with highest compliance (Table 2). In analyses of total cumulative hormonal therapy exposure, from treatment initiation to case/ control index date, the recurrence OR for women with low overall exposure was 1.62 (95\% CI 0.91, 2.88; 43 cases, 161 controls; Table 2); this was not formally significant $(P=0.11)$.

Sensitivity analyses. The results from probabilistic sensitivity analyses correcting for possible non-differential and differential misclassification of breast cancer recurrence are presented in Table 3. In these sensitivity analyses the median OR estimates for low persistence, compliance and cumulative exposure, based on 5000 simulations, were similar to estimates obtained from the primary analyses. The 95\% OR simulation limits for associations between low persistence and breast cancer recurrence did not include the null, which is compatible with results from the primary analysis. Additionally, in a analyses including patients of any age the adjusted recurrence ORs were not considerably different from those from the main analysis: non-persistence OR $=2.46$ (95\% CI
$1.00,6.07 ; 8$ cases, 17 controls); lowest compliance tertile $\mathrm{OR}=1.60$ (95\% CI $0.92,2.77 ; 41$ cases, 164 controls); lowest overall exposure tertile $\mathrm{OR}=1.66$ (95\% CI 0.97, 2.84; 45 cases, 168 controls).

\section{DISCUSSION}

In this study of 1376 women with stage I-III ER-positive breast cancer, early breast cancer recurrences were significantly more likely to occur in those who had stopped taking hormonal therapy for $\geqslant 180$ days than those who persisted with treatment. In addition, low compliance with treatment appeared to be associated with a moderately increased risk of recurrence, although associations did not reach statistical significance. These results provide evidence, in a 'real-world' clinical practice setting, to support the importance of persistence (and potentially, compliance) with hormonal therapy in the adjuvant treatment of early breast cancer. They are also consistent with the results from randomised controlled trials, which have conclusively demonstrated the benefits of longer-duration adjuvant hormonal therapy for women with early-stage ER-positive breast cancer (EBCTG, 2005; Davies et al, 2013).

A small number of prior observational studies have examined associations between hormonal therapy non-persistence and breast cancer recurrence or mortality (Hershman et al, 2011; Weaver et al, 2012). These have reported mixed results. In a study of 857 women with stage I-III breast cancer, no association was observed between hormonal therapy non-persistence and disease recurrence (OR 1.18, 95\% CI 0.76, 1.82) (Weaver et al, 2012). The absence of an association may have been due to the definition of nonpersistence used; this was assessed within in the first year of treatment only, after which patients could recommence therapy. Conversely, in a larger study of 8769 women with stage I-III breast 


\begin{tabular}{|c|c|c|c|c|}
\hline Medication-taking behaviour & $\begin{array}{c}\text { Cases }(\%)^{a} \\
(n=94)\end{array}$ & $\begin{array}{l}\text { Controls (\%) } \\
\quad(n=458)\end{array}$ & $\begin{array}{c}\text { Univariate odds ratio } \\
(95 \% \mathrm{Cl})\end{array}$ & $\begin{array}{l}\text { Multivariate } \\
\text { odds ratio } \\
(95 \% \mathrm{Cl})^{\mathrm{b}}\end{array}$ \\
\hline \multicolumn{5}{|l|}{ Persistence and compliance } \\
\hline \multicolumn{5}{|l|}{ Hormonal therapy persistence ${ }^{c, d}$} \\
\hline $\begin{array}{l}\text { Persistent } \\
\text { Non-persistent } \\
\text { (>180 day gap) }\end{array}$ & $\begin{array}{c}86(91.5) \\
8(8.5)\end{array}$ & $\begin{array}{c}444(96.9) \\
14(3.1)\end{array}$ & $\begin{array}{c}\text { Ref } \\
3.00(1.18,7.60)\end{array}$ & $\begin{array}{c}\text { Ref } \\
2.88(1.11,7.46)\end{array}$ \\
\hline \multicolumn{5}{|l|}{ Hormonal therapy compliance $e^{e, f}$} \\
\hline $\begin{array}{l}\text { High (98-100\%) } \\
\text { Intermediate (90-98\%) } \\
\text { Low (0-90\%) }\end{array}$ & $\begin{array}{l}30(31.9) \\
28(29.8) \\
36(38.3)\end{array}$ & $\begin{array}{l}154(33.6) \\
156(34.1) \\
148(32.3)\end{array}$ & $\begin{array}{c}\text { Ref } \\
0.96(0.53,1.71) \\
1.24(0.71,2.14)\end{array}$ & $\begin{array}{c}\text { Ref } \\
0.95(0.53,1.71) \\
1.30(0.74,2.30)\end{array}$ \\
\hline \multicolumn{5}{|l|}{ Cumulative exposure } \\
\hline \multicolumn{5}{|c|}{ Cumulative hormonal therapy exposure ${ }^{g}$} \\
\hline $\begin{array}{l}\text { High (98-100\%) } \\
\text { Intermediate (90-98\%) } \\
\text { Low (0-90\%) }\end{array}$ & $\begin{array}{l}24(25.5) \\
27(28.7) \\
43(45.7)\end{array}$ & $\begin{array}{l}144(31.4) \\
153(33.4) \\
161(35.2)\end{array}$ & $\begin{array}{c}\text { Ref } \\
1.04(0.57,1.91) \\
1.60(0.91,2.81)\end{array}$ & $\begin{array}{c}\text { Ref } \\
1.02(0.55,1.90) \\
1.62(0.91,2.88)\end{array}$ \\
\hline \multicolumn{5}{|c|}{ 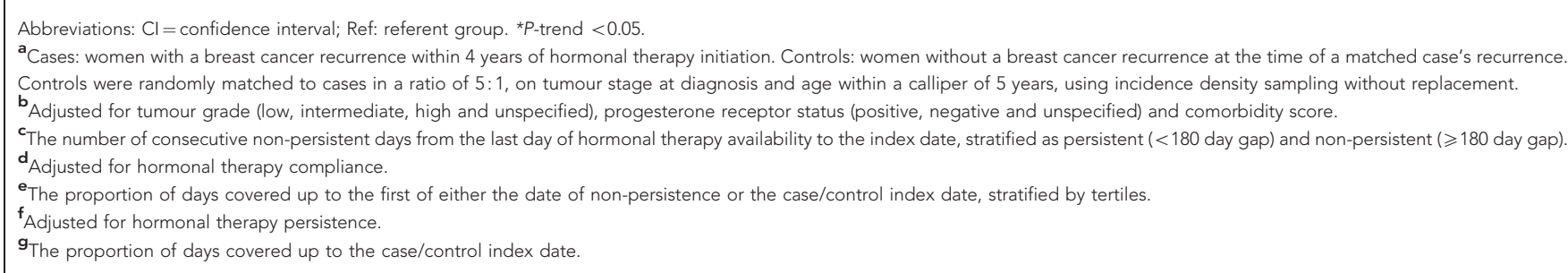 } \\
\hline
\end{tabular}

cancer, hormonal therapy non-persistence, defined as a treatment gap of 180 days, was associated with a significantly increased risk of all-cause mortality (HR 1.26, 95\% CI 1.09-1.46) (Hershman et al, 2011). However, the time-varying nature of treatment persistence does not appear to have been accounted for in these analyses and this result may underestimate the true association between hormonal therapy non-persistence and mortality (Suissa, 2007).

The moderate-albeit non-significant-association between low compliance and increased risk of breast cancer recurrence observed in this study is comparable with the results from a number of prior studies (Dezentjé et al, 2010; Weaver et al, 2012; Makubate et al, 2013). By convention, a compliance threshold of $80 \%$ and treatment gap of between 90-180 days have been used to define adjuvant hormonal therapy non-compliance and non-persistence (McCowan et al, 2008; Dezentjé et al, 2010; Hershman et al, 2011; Weaver et al, 2012; Makubate et al, 2013). However, the exact thresholds that define clinically relevant non-compliance and nonpersistence are currently unknown. The results presented here suggest that hormonal therapy treatment discontinuation is associated with a greater risk of breast cancer recurrence than low compliance. Confirmation of these findings and further elucidation of the role that different patterns of missed hormonal therapy doses have in treatment failure will require detailed data, such as that provided by electronic medication event monitoring.

In terms of clinical implications, the results from this study suggest the possibility that interventions aimed at increasing persistence with hormonal therapy could reduce recurrence rates in women with early breast cancer. To date, however, simple educational interventions to improve hormonal therapy compliance and persistence have had limited success (Hadji et al, 2012).
It is likely that the systematic development of a theoretically based intervention to target modifiable risk factors for non-persistence may be required. The reasons for hormonal therapy nonpersistence were not available for this study. Previous studies have however reported that side effects strongly influence a woman's decision to discontinue treatment (Grunfeld et al, 2005; Henry et al, 2012), suggesting that an intervention might focus on (i) the early identification of women experiencing side effects; (ii) the availability of effective supportive pharmacologic and psychological care and (iii) the timely switching to alternative hormonal therapies where appropriate (Henry et al, 2012).

The strengths of this study include the use of high-quality prospectively collected, population-based, prescription and cancer registry data. Cases and controls were also sampled from the same base population and controls were representative of the population that gave rise to the cases. However, there are a number of limitations. The number of cases/controls that contributed to the analysis of persistence was small and the results from this analysis should be interpreted with caution. The assessment of medicationtaking behaviour was based upon prescription refill data and may therefore overestimate compliance and persistence in women who fill a prescription but do not take the medication they receive. It was also not possible to validate the data on breast cancer recurrences, or to identify the number of recurrences that were biopsy proven, and the possibility that there may have been underascertainment of breast cancer recurrences must be considered. This is unlikely to have greatly influenced the observed associations for the following reasons. First, the case-control methodology employed is appropriate for use in analyses where case ascertainment may be imperfect, in particular where sensitivity may be low but specificity is likely to be very high (Brenner and Savitz, 1990), 
Table 3. Probabilistic sensitivity analyses correcting for non-differential and differential misclassification of breast cancer recurrence

\begin{tabular}{|c|c|c|c|c|c|}
\hline Sensitivity analysis ${ }^{a}$ & $\begin{array}{l}\text { Odds ratio } \\
2.5 \\
\text { percentile }\end{array}$ & $\begin{array}{l}\text { Odds ratio } \\
\text { median } \\
\text { estimate }\end{array}$ & $\begin{array}{l}\text { Odds ratio } \\
\quad 97.5 \\
\text { percentile }\end{array}$ & $\begin{array}{c}\text { Change in simulation interval } \\
\text { width (b/a) compared with } \\
\text { conventional (\%) }\end{array}$ & $\begin{array}{l}\text { Proportion of } \\
\text { simulations with } \\
\text { odds ratio }<1\end{array}$ \\
\hline \multicolumn{6}{|l|}{ Persistence-low ( $\geqslant 180$ day gap) } \\
\hline \multicolumn{6}{|l|}{ Non-differential sensitivity analysis ${ }^{b}$} \\
\hline $\begin{array}{l}\text { Sensitivity analysis only } \\
\text { Sensitivity analysis with random error }\end{array}$ & $\begin{array}{l}2.45 \\
1.39\end{array}$ & $\begin{array}{l}3.98 \\
4.00\end{array}$ & $\begin{array}{r}7.78 \\
12.30\end{array}$ & $\begin{array}{r}-51.5 \\
35.4\end{array}$ & $\begin{array}{l}0.010 \\
0.005\end{array}$ \\
\hline \multicolumn{6}{|l|}{ Differential sensitivity analysis $^{c}$} \\
\hline $\begin{array}{l}\text { Sensitivity analysis only } \\
\text { Sensitivity analysis with random error }\end{array}$ & $\begin{array}{l}2.68 \\
1.51\end{array}$ & $\begin{array}{l}4.26 \\
4.29\end{array}$ & $\begin{array}{r}7.86 \\
12.79\end{array}$ & $\begin{array}{r}-53.7 \\
34.1\end{array}$ & $\begin{array}{l}0.009 \\
0.003\end{array}$ \\
\hline \multicolumn{6}{|l|}{ Compliance-low (0\%-90\%) } \\
\hline \multicolumn{6}{|l|}{ Non-differential sensitivity analysis ${ }^{b}$} \\
\hline $\begin{array}{l}\text { Sensitivity analysis only } \\
\text { Sensitivity analysis with random error }\end{array}$ & $\begin{array}{l}1.00 \\
0.73\end{array}$ & $\begin{array}{l}1.36 \\
1.35\end{array}$ & $\begin{array}{l}1.90 \\
2.60\end{array}$ & $\begin{array}{r}-37.2 \\
17.5\end{array}$ & $\begin{array}{l}0.222 \\
0.171\end{array}$ \\
\hline \multicolumn{6}{|l|}{ Differential sensitivity analysis $^{c}$} \\
\hline $\begin{array}{l}\text { Sensitivity analysis only } \\
\text { Sensitivity analysis with random error }\end{array}$ & $\begin{array}{l}1.08 \\
0.77\end{array}$ & $\begin{array}{l}1.46 \\
1.46\end{array}$ & $\begin{array}{l}2.12 \\
2.81\end{array}$ & $\begin{array}{r}-38.5 \\
19.8\end{array}$ & $\begin{array}{l}0.234 \\
0.124\end{array}$ \\
\hline \multicolumn{6}{|c|}{ Cumulative exposure-low (0\%-90\%) } \\
\hline \multicolumn{6}{|l|}{ Non-differential sensitivity analysis ${ }^{b}$} \\
\hline $\begin{array}{l}\text { Sensitivity analysis only } \\
\text { Sensitivity analysis with random error }\end{array}$ & $\begin{array}{l}1.32 \\
0.92\end{array}$ & $\begin{array}{l}1.80 \\
1.81\end{array}$ & $\begin{array}{l}2.61 \\
3.56\end{array}$ & $\begin{array}{r}-35.7 \\
25.3\end{array}$ & $\begin{array}{l}0.048 \\
0.042\end{array}$ \\
\hline \multicolumn{6}{|l|}{ Differential sensitivity analysis $^{c}$} \\
\hline $\begin{array}{l}\text { Sensitivity analysis only } \\
\text { Sensitivity analysis with random error }\end{array}$ & $\begin{array}{l}1.43 \\
1.01\end{array}$ & $\begin{array}{l}1.94 \\
1.96\end{array}$ & $\begin{array}{l}2.72 \\
3.67\end{array}$ & $\begin{array}{r}-40.8 \\
13.1\end{array}$ & $\begin{array}{l}0.057 \\
0.024\end{array}$ \\
\hline \multicolumn{6}{|c|}{ 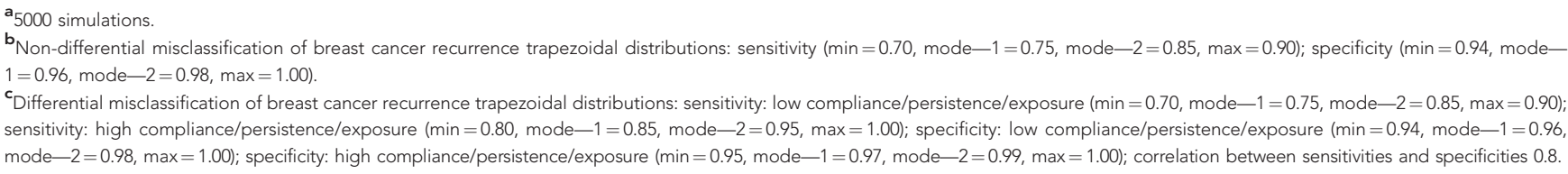 } \\
\hline
\end{tabular}

as in this study. Second, the recurrence rate observed in this study (25.6 recurrences/1000 woman-years) is broadly consistent with the recurrence rate observed for women receiving hormonal therapy for ER-positive early breast cancer in a meta-analysis of clinical studies (29.5 recurrences/1000 woman-years) (EBCTG, 2005). Third, probabilistic sensitivity analyses were undertaken to quantify the range of plausible associations in the presence of both differential and non-differential misclassification of recurrences. These indicate that the observed results are unlikely to be influenced greatly by recurrence misclassification within the range of sensitivities and specificities examined. The validity of these sensitivity analyses is however dependent on the ability to accurately specify distributions for the bias parameters, for which there was minimal prior data. One source of residual confounding should be considered as a potential explanation for the observed results. High compliance/persistence behaviour is strongly associated with other healthy behaviours (Curtis et al, 2011); consequently, observed benefits of treatment persistence may be partly attributable to other healthy behaviours (Bonadonna and Valagussa, 1981). Finally, women in this study received a range of different hormonal treatments, each with unique pharmacokinetic/dynamic properties. There was not sufficient statistical power to be able to examine these separately and care should therefore be taken in generalising the results to individual hormonal therapies.

In conclusion, this study found that hormonal therapy nonpersistence was associated with significantly higher risk of breast cancer recurrence in women with stage I-III ER-positive early breast cancer. The results of this analysis are consistent with data from randomized studies of hormonal therapy treatment duration (EBCTG, 2005; Davies et al, 2013) and have implications for the development of interventions aimed at increasing persistence with hormonal therapy.

\section{ACKNOWLEDGEMENTS}

TIB and CC are supported by the Health Research Board Ireland (HRA-2009-221, ICE-2011-9). We would like to thank the National Cancer Registry Ireland and the Irish Health Services Executive Primary Care Reimbursements Services for providing access to the data upon which this study was based. In particular, we are grateful to the Data Team at the National Cancer Registry Ireland for linking the NCR and PCRS datasets and Dr Sandra Deady for preparing the datasets for analysis. 


\section{CONFLICT OF INTEREST}

The authors declare no conflict of interest.

\section{DISCLAIMER}

The Health Research Board Ireland had no role in the study design; in the collection, analysis and interpretation of data; in the writing of the report; or in the decision to submit the paper for publication. The interpretation and reporting of these data are the responsibility of the authors and in no way should be seen as the official policy or interpretation of the National Cancer Registry Ireland or the Irish Health Services Executive Primary Care Reimbursements Services.

\section{REFERENCES}

Ahern TP, Pedersen L, Tarp M, Cronin-Fenton DP, Garne JP, Silliman RA, Sørensen HT, Lash TL (2011) Statin prescriptions and breast cancer recurrence risk: a danish nationwide prospective cohort study. J Natl Cancer Inst 103: 1461-1468.

Austin PC (2008) Assessing balance in measured baseline covariates when using many-to-one matching on the propensity-score. Pharmacoepidemiol Drug Saf 17: 1218-1225.

Barron TI, Bennett Kathleen, Feely J (2010) A competing risks prescription refill model of compliance and persistence. Value Health 13: 796-804.

Barron TI, Connolly R, Bennett K, Feely J, Kennedy MJ (2007) Early discontinuation of tamoxifen. Cancer 109: 832-839.

Benner JS, Glynn RJ, Mogun H, Neumann PJ, Weinstein MC, Avorn J (2002) Long-term persistence in use of statin therapy in elderly patients. JAMA 288: 455-461.

Bergstralh EJ, Kosanke JL (1995) Computerized matching of controls (Section of Biostatistics Technical Report No. 56). Mayo Foundation.

Bonadonna G, Valagussa P (1981) Dose-response effect of adjuvant chemotherapy in breast cancer. $N$ Engl J Med 304: 10-15.

Bosco JLF, Lash TL, Prout MN, Buist DSM, Geiger AM, Haque R, Wei F, Silliman RA (2009) Breast cancer recurrence in older women five to ten years after diagnosis. Cancer Epidemiol Biomarkers Prev 18: 2979-2983.

Bradley CJ, Given CW, Roberts C (2002) Race, socioeconomic status, and breast cancer treatment and survival. J Natl Cancer Inst 94: 490-496.

Braithwaite D, Izano M, Moore DH, Kwan ML, Tammemagi MC, Hiatt RA, Kerlikowske K, Kroenke CH, Sweeney C, Habel L, Castillo A, Weltzien E, Caan B (2012) Smoking and survival after breast cancer diagnosis: a prospective observational study and systematic review. Breast Cancer Res Treat 136: 521-533.

Brenner H, Savitz DA (1990) The effects of sensitivity and specificity of case selection on validity, sample size, precision, and power in hospital-based case-control studies. Am J Epidemiol 132: 181-192.

Curtis JR, Larson JC, Delzell E, Brookhart MA, Cadarette SM, Chlebowski R, Judd S, Safford M, Solomon DH, Lacroix AZ (2011) Placebo adherence, clinical outcomes, and mortality in the women's health initiative randomized hormone therapy trials. Med Care 49: 427-435.

Davies C, Pan H, Godwin J, Gray R, Arriagada R, Raina V, Abraham M, Alencar VHM, Badran A, Bonfill X, Bradbury J, Clarke M, Collins R, Davis SR, Delmestri A, Forbes JF, Haddad P, Hou M-F, Inbar M, Khaled H, Kielanowska J, Kwan W-H, Mathew BS, Müller B, Nicolucci A, Peralta O, Pernas F, Petruzelka L, Pienkowski T, Rajan B, Rubach MT, Tort S, Urrútia G, Valentini M, Wang Y, Peto R (2013) Long-term effects of continuing adjuvant tamoxifen to 10 years versus stopping at 5 years after diagnosis of oestrogen receptor-positive breast cancer: ATLAS, a randomised trial. Lancet 381: 805-816.

Debled M, MacGrogan G, Brouste V, Mathoulin-Pelissier S, Durand M, Mauriac L (2007) Prognostic factors of early distant recurrence in hormone receptor-positive, postmenopausal breast cancer patients receiving adjuvant tamoxifen therapy: results of a retrospective analysis. Cancer 109: 2197-2204.

Dezentjé VO, van Blijderveen NJC, Gelderblom H, Putter H, van Herk-Sukel MPP, Casparie MK, Egberts ACG, Nortier JWR, Guchelaar H-J (2010) Effect of concomitant CYP2D6 inhibitor use and tamoxifen adherence on breast cancer recurrence in early-stage breast cancer. J Clin Oncol 28: 2423-2429.

EBCTG (2005) Effects of chemotherapy and hormonal therapy for early breast cancer on recurrence and 15-year survival: an overview of the randomised trials. Lancet 365: 1687-1717.

Fox MP, Lash TL, Greenland S (2005) A method to automate probabilistic sensitivity analyses of misclassified binary variables. Int J Epidemiol 34: 1370-1376.

Greene FL, Page DL, Fleming ID, Fritz A, Balch CM, Haller DG, Morrow M (2002) AJCC Cancer Staging Manual. 6th edn, Springer: New York.

Grunfeld EA, Hunter MS, Sikka P, Mittal S (2005) Adherence beliefs among breast cancer patients taking tamoxifen. Patient Edu Couns 59: 97-102.

Hadji P, Blettner M, Harbeck N, Jackisch C, Lück HJ, Windemuth-Kieselbach C, Zaun S, Kreienberg R (2012) The Patient's Anastrozole Compliance to Therapy (PACT) Program: a randomized, in-practice study on the impact of a standardized information program on persistence and compliance to adjuvant endocrine therapy in postmenopausal women with early breast cancer. Ann Oncol 24(6): 1505-1512.

Henry NL, Azzouz F, Desta Z, Li L, Nguyen AT, Lemler S, Hayden J, Tarpinian K, Yakim E, Flockhart DA, Stearns V, Hayes DF, Storniolo AM (2012) Predictors of aromatase inhibitor discontinuation as a result of treatment-emergent symptoms in early-stage breast cancer. J Clin Oncol 30: $936-942$.

Hershman DL, Shao T, Kushi LH, Buono D, Tsai WY, Fehrenbacher L, Kwan M, Gomez SL, Neugut AI (2011) Early discontinuation and non-adherence to adjuvant hormonal therapy are associated with increased mortality in women with breast cancer. Breast Cancer Res Treat 126: 529-537.

Holmes MD, Chen WY, Li L, Hertzmark E, Spiegelman D, Hankinson SE (2010) Aspirin intake and survival after breast cancer. J Clin Oncol 28: 1467-1472.

Jurek AM, Lash TL, Maldonado G (2009) Specifying exposure classification parameters for sensitivity analysis: family breast cancer history. Clin Epidemiol 1: 109-117.

Kelly A, Teljeur C. Small Area Health Research Unit, Department of Public Health and Primary Care, Trinity College Dublin (2007) National Deprivation Index for Health Services and Health Services Research (Technical Report).

Kennecke H, McArthur H, Olivotto IA, Speers C, Bajdik C, Chia SK, Ellard S, Norris B, Hayes M, Barnett J, Gelmon KA (2008) Risk of early recurrence among postmenopausal women with estrogen receptor-positive early breast cancer treated with adjuvant tamoxifen. Cancer 112: 1437-1444.

Lash TL, Fink AK (2003) Semi-automated sensitivity analysis to assess systematic errors in observational data. Epidemiology 14: 451-458.

Lash TL, Fox MP, Fink AK (2009) Applying Quantitative Bias Analysis to Epidemiologic Data. 1st edn, Springer.

Lash TL, Fox MP, Thwin SS, Geiger AM, Buist DSM, Wei F, Field TS, Yood MU, Frost FJ, Quinn VP, Prout MN, Silliman RA (2007) Using probabilistic corrections to account for abstractor agreement in medical record reviews. Am J Epidemiol 165: 1454-1461.

Makubate B, Donnan PT, Dewar JA, Thompson AM, McCowan C (2013) Cohort study of adherence to adjuvant endocrine therapy, breast cancer recurrence and mortality. Br J Cancer 108(7): 1515-1524.

Maldonado G, Greenland S (1993) Simulation study of confounder-selection strategies. Am J Epidemiol 138: 923-936.

Mansell J, Monypenny IJ, Skene AI, Abram P, Carpenter R, Gattuso JM, Wilson CR, Angerson WJ, Doughty JC (2009) Patterns and predictors of early recurrence in postmenopausal women with estrogen receptorpositive early breast cancer. Breast Cancer Res Treat 117: 91-98.

McCowan C, Shearer J, Donnan PT, Dewar JA, Crilly M, Thompson AM, Fahey TP (2008) Cohort study examining tamoxifen adherence and its relationship to mortality in women with breast cancer. Br J Cancer 99: 1763-1768.

NCRI (2012) Data Quality and Completeness at the Irish National Cancer Registry (Technical Report). National Cancer Registry Ireland.

Owusu C, Buist DSM, Field TS, Lash TL, Thwin SS, Geiger AM, Quinn VP, Frost F, Prout M, Yood MU, Wei F, Silliman RA (2008) Predictors of tamoxifen discontinuation among older women with estrogen receptorpositive breast cancer. J Clin Oncol 26: 549-555.

Partridge AH, Wang PS, Winer EP, Avorn J (2003) Nonadherence to adjuvant tamoxifen therapy in women with primary breast cancer. J Clin Oncol 21: 602-606.

Pearce N (1993) What does the odds ratio estimate in a case-control study? Int J Epidemiol 22: 1189-1192. 
Peterson AM, Nau DP, Cramer JA, Benner J, Gwadry-Sridhar F, Nichol M (2007) A checklist for medication compliance and persistence studies using retrospective databases. Value Health 10: 3-12.

Robins JM, Gail MH, Lubin JH (1986) More on 'Biased selection of controls for case-control analyses of cohort studies'. Biometrics 42: 293-299.

Rothman KJ, Greenland S, Lash TL (eds) (2008) Modern Epidemiology. 3rd edn, Lippincott Williams \& Wilkins: Philadelphia, PA, pp 128-147.

Saphner T, Tormey DC, Gray R (1996) Annual hazard rates of recurrence for breast cancer after primary therapy. J Clin Oncol 14: 2738-2746.

Schneeweiss S, Seeger JD, Maclure M, Wang PS, Avorn J, Glynn RJ (2001) Performance of comorbidity scores to control for confounding in epidemiologic studies using claims data. Am J Epidemiol 154: $854-864$.

Suissa S (2007) Immortal time bias in observational studies of drug effects. Pharmacoepidemiol Drug Saf 16: 241-249.
Thwin SS, Clough-Gorr KM, McCarty MC, Lash TL, Alford SH, Buist DSM, Enger SM, Field TS, Frost F, Wei F, Silliman RA (2007) Automated interrater reliability assessment and electronic data collection in a multi-center breast cancer study. BMC Med Res Methodol 7: 23.

Weaver KE, Camacho F, Hwang W, Anderson R, Kimmick G (2012) Adherence to adjuvant hormonal therapy and its relationship to breast cancer recurrence and survival among low-income women. Am J Clin Oncol 36(2): 181-187.

WHO (2010) ATC classification index with DDDs 2011. WHO Collaborating Centre for Drug Statistics Methodology: Oslo.

This work is published under the standard license to publish agreement. After 12 months the work will become freely available and the license terms will switch to a Creative Commons AttributionNonCommercial-Share Alike 3.0 Unported License. 